\title{
PERSEPSI UMKM TERHADAP PEMANFAATAN E-COMMERCE e-SIATIK (ternakitik.com) DI KABUPATEN BREBES
}

\author{
Suci Nur Utamii), Nur Ariesanto Ramdhan²), Suci Paramitasari Syahlani3), Rini \\ Widiati $\left.^{4}\right)$ \\ 1)Fakultas Sains dan Teknologi, Program Studi Agribisnis, Universitas Muhadi Setiabudi, Jl. P. \\ Diponegoro KM 2 Pesantunan Brebes, Telp (0283) 6199000, email:sucinurutami@umus.ac.id \\ 2) Fakultas Teknik, Program Studi Teknik Informatika, Universitas Muhadi Setiabudi, Jl. P. Diponegoro \\ KM 2 Pesantunan Brebes, Telp (0283) 6199000, email:ariesantoramdhan@gmail.com \\ 3,4) Fakultas Peternakan, Departemen Sosial Ekonomi Peternakan, Universitas Gadjah Mada, Jl. \\ Fauna No 3 Bulaksumur Yogyakarta 55281, Telp (0274) 513363, email: suci.syahlani@ugm.ac.id, \\ email:rini_w@ugm.ac.id
}

\begin{abstract}
Abstrak
Perancangan website e-siatik dimaksudkan untuk mengatasi permasalahan turunnya omset penjualan yang dialami oleh sebagian pelaku usaha di bidang industri telur asin. Sasarannya adalah industri telur asin yang masuk kategori UMKM. Sehingga UMKM dapat bersaing dengan industri-industri lain yang sudah mempunyai skala usaha yang besar. Penelitian ini bertujuan untuk mengetahui persepsi UMKM terhadap perancangan website E-commerce E-siatik (ternakitik.com) di Kabupaten Brebes. Penelitian dilakukan dengan metode survei dengan pengambilan data menggunakan teknik random sampling. Data penelitian dibagi menjadi data primer dan data sekunder. Data primer diperoleh dari hasil wawancara dengan 40 responden pemilik UMKM dan data sekunder diperoleh dari literatur yang mendukung bagi penelitian ini. Analisis data menggunakan skala likert dengan bantuan instrumen penelitian berupa kuesioner. Hasil penelitian menunjukkan bahwa persepsi masyarakat terhadap perancangan website E-commerce E-Siatik tergolong baik dengan indeks sebesar $73,13 \%$. Penggunaan media e-siatik menjadi harapan baru bagi para pelaku UMKM untuk memperluas jangkauan pemasaran dan menghemat biaya promosi yang harus dikeluarkan.
\end{abstract}

Kata kunci: , e-siatik, persepsi, ternakitik.com, UMKM

\begin{abstract}
The design of e-siatik website is intended to overcome the problem of falling sales turnover experienced by some businesses in the salt egg industry. The target is the salted egg industry that is in the SMEs category. So that SMEs can compete with other industries that already have a large business scale. This research aims to determine the perception of SMEs towards the designing E-commerce website (ternakitik.com) in Brebes County. Research data is divided into primary data and secondary data. The primary data is derived from interviews with 40 respondents of SMEs and secondary data is derived from the supporting literature for this study. Research is conducted by surveying methods with data retrieval using random sampling techniques. Data analysis uses the Likert scale with the help of research instruments in the form of questionnaires. The results showed that the public perception of E-Siatik E-commerce website is relatively good with an index of 73.13\%. The use of e-Siatik Media is a new hope for SMEs actors to expand the marketing range and save on the cost of promotion that must be issued.
\end{abstract}

Keywords: e-Siatik, perception, ternakitik.com, SMEs 


\section{PENDAHULUAN}

Internet merupakan satu sistem komputer yang terkoneksi dengan jaringan global dan berfungsi sebagai media informasi dan komunikasi. Teknologi internet telah dimanfaatkan oleh sebagian besar masyarakat Indonesia sekarang ini. Penggunaan internet tentunya mempermudah masyarakat dalam memenuhi kebutuhan hidup. Sebelumnya, internet hanya menyediakan informasi yang dapat diakses oleh pengguna di setiap waktu dan dapat dijadikan sebagai media komunikasi sebagai pelengkap telepon. Namun dalam perkembangannya, fungsi internet semakin meluas salah satunya sebagai sarana transaksi bisnis.

E-commerce merupakan sarana bisnis yang dilakukan melalui jaringan internet. Ecommerce secara perlahan dapat menyaingi transaksi bisnis konvensional yang menawarkan kemudahan dalam melakukan transaksi jual beli barang/jasa. E-commerce terbagi menjadi tiga jenis konsep bisnis yaitu konsep Business to Business (B2B), Business to Consumer (B2C), dan Consumer to Consumer (C2C). Business to Business (B2B) merupakan transaksi bisnis e-commerce antar pelaku bisnis, contohnya bisnis antara perusahaan McAfee dengan Yahoo, Business to Consumer (B2C) merupakan transaksi bisnis e-commerce antara perusahaan dengan pengguna contohnya Tokopedia, Bukalapak, dan Lazada. Sedangkan Consumer to Consumer (C2C) merupakan transaksi e-commerce secara langsung ataupun melalui pihak ketiga contohnya adalah OLX.com. Kelebihan e-commerce diantaranya adalah mempersingkat waktu dan biaya, pelayanan cepat, dan menawarkan lebih banyak barang dengan berbagai macam harga dan kualitas. Pemasaran barang melalui e-commerce pastinya secara tidak langsung dapat meningkatkan volume penjualan apabila prdouk yang ditawarkan oleh produsen mempunyai nilai lebih daripada produk yang lainnya.

Kabupaten Brebes merupakan salah satu daerah di ujung barat Provinsi Jawa Tengah. Pada tahun 2024, Kabupaten Brebes telah ditetapkan sebagai kawasan industri di Jawa Tengah. Oleh karena itu, industriindustri lokal yang ada di Kabupaten Brebes perlu lebih ditingkatkan nilai jualnya supaya tidak kalah saing dengan industri-industri yang dimiliki oleh investor dari luar Kabupaten Brebes.

Salah satu industri di Kabupaten Brebes adalah industri telur asin. Cukup banyak pelaku usaha yang bergerak di bidang pengolahan telur asin tersebut. Selama ini, industri telur asin masih mengandalkan penjualan konvensional di outlet dalam pemasarannya. Hanya sebagian kecil pelaku usaha yang telah memanfaatkan internet sebagai media pemasaran. Sehingga penjualan telur asin hanya meningkat pada saat musim-musim tertentu ketika banyak masyarakat yang singgah di Kabupaten Brebes. Apalagi, dengan adanya jalan tol yang melewati Kabupaten Brebes, masyarakat luar kota yang melewati Kabupaten Brebes dipastikan turun karena lebih memilih alternatif jalan tol. Dampaknya omset penjualan telur asin tidak sebanyak saat belum adanya jalan tol.

Perancangan website e-siatik dimaksudkan untuk mengatasi permasalahan turunnya omset penjualan yang dialami oleh sebagian pelaku usaha di bidang industri telur asin. Sasarannya adalah industri telur asin yang masuk kategori UMKM. Sehingga UMKM dapat bersaing dengan industriindustri lain yang sudah mempunyai skala usaha yang besar. Perlu kajian lebih mendalam untuk mengetahui keberhasilan penggunaan e-commerce e-siatik dalam meningkatkan penjualan telur asin di Kabupaten Brebes. Hal utama yang perlu diketahui adalah persepsi UMKM sendiri terhadap adanya website e-siatik. Dengan memahami persepsi UMKM, dapat diketahui design dan konten website yang mudah digunakan oleh UMKM. Sehingga UMKM tidak mengalami kesulitan dalam penggunaan website e-siatik. Penggunaan website sebagai media pemasaran diharapkan memberikan dampak yang positif bagi peningkatan kesejahteraan dan skala usaha UMKM telur asin di Kabupaten Brebes. Tingginya dampak sosial ekonomi yang didapat dari perancangan website e-siatik tentunya sangat mempengaruhi persepsi UMKM (Klasibin et al., 2018). 
Rumusan masalah dalam penelitian ini adalah bagaimana persepsi UMKM telur asin terhadap website e-commerce e-siatik di Kabupaten Brebes. Penelitian ini bertujuan untuk menggambarkan persepsi UMKM telur asin terhadap website e-commerce e-siatik.

\section{BAHAN DAN METODE}

\section{Bahan}

Bahan utama yang digunakan dalam penelitian ini adalah website e-siatik (ternakitik.com) yang dirancang oleh Universitas Muhadi Setiabudi. Perancangan website dilakukan di bawah bimbingan Departemen Sosial Ekonomi Peternakan Universitas Gadjah Mada sebagai mitra dari penelitian ini.

\section{Metode}

Data penelitian diambil dengan metode wawancara, observasi, dan dokumentasi. Data yang digunakan terdiri dari data primer dan data sekunder. Data primer diambil dari data langsung dari responden melalui wawancara. Data sekunder merupakan sumber data bukan dari sumber aslinya (Klasibin et al., 2018). Data sekunder diambil dari data penelitian terdahulu, data UMKM, maupun data instansi terkait.

Sampel penelitian diambil dengan menggunakan metode simple random sampling. Objek penelitian dalam penelitian ini adalah UMKM di Kabupaten Brebes. Responden berjumlah 40 orang responden.

Metode yang digunakan dalam penelitian ini adalah metode deskriptif. Metode analisis deskriptif bertujuan untuk memberikan gambaran peristiwa, kejadian, atau fenomena tertentu yang diinterpretasikan dengan menggunakan skala likert. Analisis deskriptif bertujuan untuk memahami lebih mendalam tentang setiap permasalahan sosial ekonomi dan interaksi manusia dan untuk mendapatkan jawaban yang lebih dalam mengenai suatu fenomena sosial ekonomi (Klasibin et al., 2018). Analisis data dengan menggunakan skala likert dengan ketentuan sebagai berikut:

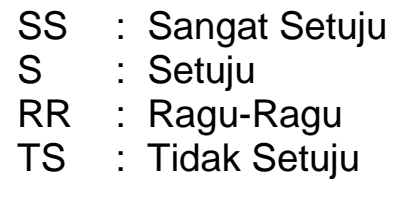

Skor 5 : Skor 4 : Skor 3 : Skor 2

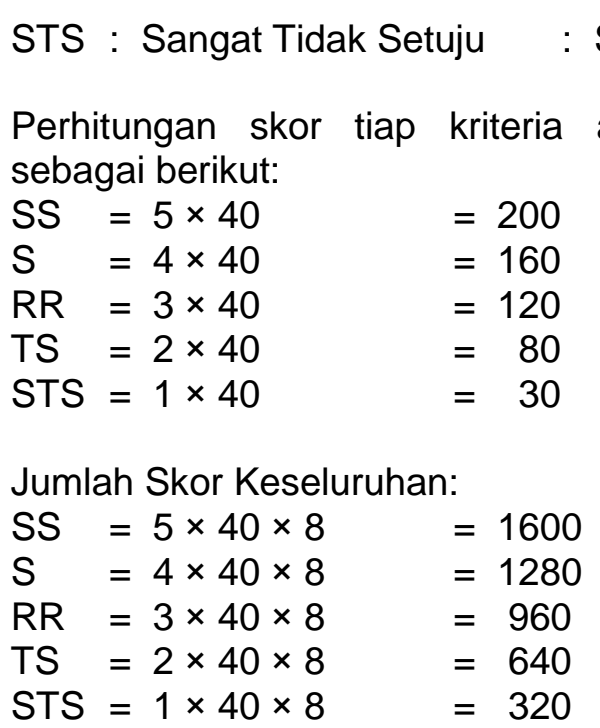

Tingkat persepsi dihitung dengan rumus sebagai berikut:

Tingkat Persepsi $=\frac{\text { Skor Keseluruhan }}{\text { Skor tertinggi }} \times 100 \% \ldots . .(1)$

Kriteria interpretasi skor persepsi UMKM telur asin terhadap website e-siatik adalah:

$0 \%-20 \%=$ Sangat Tidak Baik

$21 \%-40 \%=$ Buruk

$41 \%-60 \%=$ Kurang Baik

$61 \%-80 \%=$ Baik

$81 \%-100 \%=$ Sangat Baik (Nagapa et al., 2019)

\section{HASIL DAN PEMBAHASAN}

\section{Deskripsi Wilayah Penelitian}

Luas wilayah Kabupaten Brebes adalah 1.769,62 $\mathrm{km}^{2}$ yang terbagi menjadi 17 kecamatan dan 297 desa. Kecamatan Bantarkawung merupakan kecamatan terluas dengan luas wilayah 208,18 $\mathrm{km}^{2}$ dan Kecamatan Kersana merupakan kecamatan terkecil dengan luas wilayah $26,97 \mathrm{~km}^{2}$. Kabupaten Brebes membentang di sepanjang Pantai Utara Laut Jawa yang merupakan daerah otonomi di Provinsi Jawa Tengah. Wilayah selatan berbatasan dengan Karesidenan Banyumas, sebelah timur dengan Kota Tegal dan Kabupaten Tegal, dan sebelah barat dengan Provinsi Jawa Barat. Wilayah Kabupaten Brebes bagian utara merupakan dataran rendah sedangkan bagian selatan berupa dataran tinggi. Kecamatan Sirampog merupakan kecamatan tertinggi 
dengan ketinggian berkisar $875 \mathrm{~m}$ (BPS Kabupaten Brebes, 2019).

Jumlah penduduk di Kabupaten Brebes berdasarkan survei pada tahun 2018 adalah sebanyak 1.802.829 jiwa dengan perbandingan jumlah penduduk laki-laki lebih banyak daripada penduduk perempuan. Jumlah penduduk laki-laki sebesar 905.683 jiwa dan perempuan sebanyak 897.146 jiwa. Laju pertumbuhan penduduk rata-rata per tahun adalah sebesar 0,48 persen. Sebagian besar penduduk di Kabupaten Brebes tergolong dalam usia muda yaitu kelompok umur 10 - 14 tahun dan 15 - 19 tahun walaupun secara umum jumlah penduduk produktif lebih banyak dari penduduk tidak produktif yaitu usia di bawah 15 tahun dan di atas 65 tahun.

Angkatan kerja di Kabupaten Brebes sebesar 897.629 orang pada tahun 2018 terdiri dari 832.405 orang yang bekerja dan 65.224 pengangguran terbuka dengan 441.510 termasuk bukan angkatan kerja. Lapangan kerja di Kabupaten Brebes didominasi oleh sektor pertanian. 279.913 orang penduduk bekerja di sektor tersebut (BPS Kabupaten Brebes, 2019).

\section{Website e-Siatik (ternakitik.com)}

Website e-siatik merupakan sebuah website e-commerce yang ditujukan untuk UMKM telur asin dan peternak itik di Kabupaten Brebes. Bagi UMKM, website esiatik berfungsi sebagai pendukung media pemasaran supaya tingkat penjualan meningkat. Sasaran pengguna website esiatik adalah UMKM telur asin yang masih mempunyai skala yang rendah. Harapannya adalah supaya dapat bersaing dengan produsen telur asin yang berskala besar.

Sasaran kedua adalah peternak itik di Kabupaten Brebes. Telur itik merupakan bahan baku utama pembuatan telur asin yang merupakan produk unggulan andalan yang dimiliki oleh Kabupaten Brebes. Website esiatik diharapkan dapat meningkatkan penjualan telur itik produksi peternak di Kabupaten Brebes supaya dapat terjalin sinergisitas antara peternak itik dan produsen telur asin di Kabupaten Brebes.

Selama ini, sebagian besar produsen telur asin di Kabupaten Brebes memasok bahan baku telur itik dari luar daerah
Kabupaten Brebes. Kondisi ini tentunya dapat menghambat perkembangan usaha peternak itik dalam pemasaran produknya. Tingginya permintaan telur asin tidak diimbangi dengan tingginya permintaan telur itik produksi peternak di Kabupaten Brebes. Website esiatik diperkenalkan kepada peternak itik agar peternak dapat memanfaatkan teknologi internet dan mengaplikasikan dalam pemasaran produk. Penggunaan ecommerceakan mempermudah kinerja perusahaan dan meningkatkan kualitas usaha, dapat memperluas pangsa pasar dengan lebih menekan biaya promosi (Harisno dan Pujadi, 2009).

Perlu adanya perhatian dari pemerintah yang dapat dilakukan dengan cara sosialisasi dan pemberian keterampilan dalam ecommerce ternak itik dan produsen telur asin supaya timbul semangat bagi para calon pengguna e-commerce (Nagapa et al., 2019).

\section{Persepsi Pelaku UMKM terhadap Pemanfaatan Website e-Siatik (ternakitik.com)}

Persepsi merupakan inti dari sebuah proses komunikasi dimana persepsi akan kejujuran dari yang lain (masyarakat) dapat mempengaruhi perilaku kepatuhan. Persepsi memiliki pengaruh yang sangat kuat dalam proses pengambilan keputusan (Fida \& Widyaningsih, 2017). Persepsi pada keberadaan e-commerce bagi sebagian masyarakat dianggap sangat efektif dan dan memudahkan produsen konsumen yang menggunakan karena e-commerce merupakan trend belanja masa kini (Saflianda et al., 2017). E-commerce melalui website termasuk lebih aman dan menyediakan kualifikasi produk tertentu yang memudahkan konsumen dalam mencari produk (Saflianda et al., 2017).

Persepsi diawali dengan adanya stimuli yang mengenai panca indera dan disebut sensasi. Stimuli dapat didapat dari faktor dalam maupun di luar diri individu. Faktor yang berasal dari dalam adalah motivasi dan faktor dari luar adalah perbedaan yang mencolok, kebaruan, intensitas, ukuran objek, gebrakan, dan pengulangan. Faktor dari luar tersebut yang akan menarik perhatian konsumen dan secara perlahan akan masuk dalam pikiran konsumen (Yusuf et al., 2018). Oleh karena itu 
dalam pemanfaatan e-commerce perlu lebih menekankan faktor dari luar individu tersebut.

\section{Persepsi tentang Kemudahan Penggunaan Website e-Siatik (ternakitik.com)}

Terdapat dua indikator yang digunakan dalam pengukuran persepsi UMKM telur asin terhadap kemudahan penggunaan website esiatik yaitu kemudahan dalam mengakses website dan kepraktisan dalam menggunakan berbagai fasilitas yang disediakan dalam website. Prosedur-prosedur yang digunakan dalam penjualan dan transaksi telah disediakan dalam website sehingga UMKM sebagai pengguna tidak mengalami kesulitan dalam memasarkan telur asin melalui website.

Persepsi UMKM terhadap sosialisasi website menunjukkan bahwa skor responden terbanyak adalah pada kategori sangat setuju sebanyak 22 orang $(55 \%)$. Website e-siatik menjadi cara pemasaran baru yang efektif untuk meningkatkan volume penjualan telur asin. Indonesia telah memiliki modal yang kuat dalam dengan banyaknya model bisnis ecommerce. Perlu langkah dan strategi yang tepat untuk mendorong peningkatan jumlah UMKM yang memanfaatkan e-commerce ini. Perlu adanya sinergi dari seluruh stakeholder mulai dari akademisi, pebisnis, pemerintah, media dan komunitas dalam bentuk sosialisasi maupun pelatihan-pelatihan yang akan berkontribusi dalam adopsi e-commerce bagi UMKM secara menyeluruh, bertahap, dan berkesinambungan (Febriantoro, 2016).

\section{Persepsi UMKM Telur Asin tentang Kemudahan Penggunaan Website e-Siatik (ternakitik.com)}

Lampiran Tabel 2 menunjukkan bahwa skor responden terbanyak adalah pada kategori setuju sebanyak 18 orang (45\%). Menurut responden, e-commerce e-siatik tergolong mudah untuk digunakan karena telah tersedia petunjuk dalam melakukan transaksi penjualan dan pembelian produk. Kemudahan penggunaan e-commerce akan berpengaruh pada keputusan pembelian online. Kemudahan akan menimbulkan kepercayaan konsumen terhadap suatu sistem e-commerce yang mana kepercayaan memberikan pengaruh yang dominan dalam keputusan pembelian secara online (Ardyanto et al., 2015).

Semakin tinggi kemudahan yang dirasakan oleh pengguna maka akan semakin tinggi pula tingkat kepercayaan. Kemudahan merupakan pengetahuan pembeli tentang $e$ commerce dan tidak mempersulit ketika pengguna akan melakukan pembelian secara online (Romla dan Ratnawati, 2018).

\section{Persepsi UMKM Telur Asin tentang Kepraktisan Penggunaan Website e-Siatik (ternakitik.com)}

Lampiran Tabel 3 menunjukkan bahwa skor responden terbanyak adalah pada kategori setuju sebanyak 14 orang (35\%). Menurut responden, website e-siatik merupakan suatu media pemasaran yang cukup praktis karena hanya membutuhkan seperangkat komputer atau smartphone dalam pengoperasian website. Kebutuhan akan proses transaksi online yang cepat, praktis, dan efisien akan sangat berpengaruh terhadap perkembangan e-commerce terutama e-commerce e-siatik ini (Firmansyah, 2017).

\section{Persepsi UMKM Telur Asin tentang Kerumitan Penggunaan Website e-Siatik (ternakitik.com) \\ Lampiran Tabel 4 menunjukkan bahwa} skor responden terbanyak adalah pada kategori ragu-ragu sebanyak 20 orang $(50 \%)$. Sebagian besar responden memilih jawaban ragu-ragu karena website e-siatik belum sepenuhnya digunakan sebagai media pemasaran. Sosialisasi yang diberikan hanya sebatas pengenalan adanya e-commerce esiatik. Kerumitan dalam penggunaan ecommerce tentunya akan mempengaruhi minat konsumen dalam berbelanja online.

E-commerce merupakan satu contoh dari kemajuan teknologi dimana transaksi bisnis tidak lagi dilakukan secara konvensional yang mengharuskan pembeli berinteraksi langsung dengan penjual dan tidak adanya keharusan menggunakan uang tunai dalam proses transasi. Proses transaksi diwakili oleh satu sistem online melalui jaringan internet. Oleh karena itu, ecommerce membutuhkan infrastruktur yang mampu menjamin keamanan transaksi dan tidak menyulitkan pengguna dalam penggunaannya (Lukito, 2017). 


\section{Persepsi UMKM Telur Asin tentang Keefektifan Penggunaan Website E-Siatik (ternakitik.com)}

Lampiran Tabel 5 menunjukkan bahwa skor responden terbanyak adalah pada kategori setuju sebanyak 15 orang (37,5\%). Efektivitas berpengaruh pada motivasi penggunaan e-commerce. Motivasi akan menggerakkan manusia untuk menampilan tingkah laku ke arah pencapaian tujuan (Seprina et al., 2016).

\section{Persepsi UMKM Telur Asin tentang Tampilan Website E-Siatik (ternakitik.com) \\ Lampiran Tabel 6 menunjukkan bahwa skor responden terbanyak adalah pada kategori setuju sebanyak 12 orang (30\%). Tampilan merupakan kesan pertama yang akan menentukan evaluasi pengguna e- commerce dan akan mempengaruhi persepsi dan perilaku. Aspek estetika dapat mempengaruhi tingkat kepuasan pengguna dan motivasi belanja pengguna (Pratama et al., 2014).}

\section{Persepsi UMKM Telur Asin tentang Warna Dasar Website E-Siatik (ternakitik.com)}

Lampiran Tabel 7 menunjukkan bahwa skor responden terbanyak adalah pada kategori setuju sebanyak 18 orang (45\%). Ecommerce e-siatik telah mempunyai warna yang jelas. Resolusi warna yang seimbang dan kecepatan loading halaman serta perpaduan desain grafis yang menarik akan memuaskan pengguna dan menarik minar pembelian produk (Pratama et al., 2014).

\section{Persepsi UMKM Telur Asin tentang Isi dan Fasilitas Website E-Siatik (ternakitik.com)}

Lampiran Tabel 8 menunjukkan bahwa skor responden terbanyak adalah pada kategori sangat setuju sebanyak 25 orang (62,5\%). Tampilan sebuah e-commerce yang baik adalah menampilkan informasi yang cukup sesuai dengan yang diharapkan oleh pengguna dan idealnya didapatkan dari wawancara sengan calon pengguna. Terdapat fitur yang lengkap untuk digunakan dalam mempersiapkan kebutuhan pengguna (Sofian, 2017).

\section{Rekapitulasi Skor Total Persepsi}

Penilaian persepsi Pelaku UMKM telur asin tentang pemanfaatan website e-siatik dapat dilihat pada tabel 9 yang ada di lampiran.

Tingkat Persepsi $=\frac{1170}{1600} \times 100 \%=73,13 \%$

Berdasarkan hasil perhitungan analisis skala likert diketahui bahwa tingkat persepsi UMKM telur asin tentang pemanfaatan website e-siatik adalah sebesar $73,13 \%$. Nilai tersebut mengindikasikan bahwa persepsi UMKM telur asin termasuk dalam kategori baik (Nagapa et al., 2019).

Status sosial ekonomi yang meliputi skala usaha, tingkat pendapatan, tingkat resiko, umur, partisipasi, dan tingkat keaktifan peternak tidak mempengaruhi proses adopsi inovasi peternak (Ediset \& E, 2020). Tampilan dan kemudahan penggunaan website ecommerce e-siatik menjadi faktor yang paling berpengaruh terhadap proses adopsi inovasi peternak.

\section{SIMPULAN}

Hasil penelitian penilaian persepsi UMKM telur asin terhadap pemanfaatan e-commerce e-siatik dengan menggunakan skala likert adalah tergolong baik dengan indeks sebesar $73,13 \%$. Sebagian besar UMKM telur asin setuju dengan adanya e-commerce e-Siatik. UMKM telur asin mempunyai kepercayaan yang kuat bahwa e-commerce e-Siatik akan memberikan dampak yang baik bagi perkembangan UMKM telur asin. Ecommerce e-Siatik merupakan langkah yang efektif dan efisien dalam peningkatan strategi pemasaran terutama bagi UMKM telur asin di Kabupaten Brebes.

\section{DAFTAR PUSTAKA}

Ardyanto, D., Susilo, H., \& Riyadi. (2015). Pengaruh Kemudahan dan Kepercayaan Menggunakan E-Commerce terhadap Keputusan Pembelian Online (Survei pada Konsumen www.petersaysdenim.com). Jurnal Administrasi Bisnis (JAB), 22(1), 1-8.

BPS. (2019). Kabupaten Brebes dalam Angka 2019.

Ediset, \& E, H. (2020). Posisi Status Sosial Ekonomi Peternak Sapi Potong dalam Proses Adopsi Bioteknologi Reproduksi 
di Kabupaten Dharmasraya, Sumatera Barat. Jurnal Peternakan Indonesia 22(1), 56-65.

Febriantoro, W. (2016). Kajian dan Strategi Pendukung Perkembangan ECommerce Bagi UMKM di Indonesia. Manajerial, 3(5), 184-207.

Fida, A., \& Widyaningsih, A. (2017). Persepsi Wajib Pajak Mengenai Penerapan EFaktur terhadap Kepatuhan Wajib Pajak. Proceedings Profesionalisme Akuntan Menuju Sustainable Business Practise, 884-894.

Firmansyah, A. (2017). Kajian Kendala Implementasi E-Commerce di Indonesia *. Jurnal Masyarakat Telematika dan Informasi, 8(2), 127-136.

Harisno, \& Pujadi, T. (2009). E-Business dan E-Commerce sebagai Trend Taktik Baru Perusahaan. CommIT, 3(2), 66-69.

Klasibin, J. A., Pakasi, C. B. D., \& Talumingan, C. (2018). Persepsi Masyarakat terhadap Dampak Sosial Ekonomi dari Perusahaan Perkebunan Kelapa Sawit PT Henrison Inti Persada Kabupaten Sorong Papua Barat. Agri-Sosioekonomi, 14(1), 321-334. https://doi.org/10.1017/CBO9781107415 324.004

Lukito, I. (2017). Tantangan Hukum dan Peran Pemerintah dalam Pembangunan ECommerce. JIKH, 11(3), 349-367.

Nagapa, Y., Rumagit, G. A. Y., \& Pakasi, C. B. D. (2019). Persepsi Petani Sayuran Kubis, Petsai dan Wortel terhadap Pestisida Organik di Kelurahan Kakaskasen III Kecamatan Tomohon Utara Kota Tomohon. AgriSosioekonomi, 15(2), 331-340.

Pratama, R. D., Suyadi, I., \& Susilo, H. (2014). Persepsi User terhadap Desain Website eCommerce (Studi Pada Pengguna Website JKM Store ). Jurnal Administrasi Bisnis (JAB), 9(1), 1-6.

Romla, S., \& Ratnawati, A. (2018). Keputusan Pembelian
Kemudahan Penggunaan, Kualitas Informasi dan Kualitas Interaksi Layanan Web. EKOBIS, 19(1), 59-70.

Saflianda, S., Putra, C., Indraningrat, K., \& Halim, A. (2017). Persepsi Mahasiswa Terhadap E-commerce melalui Facebook di Kecamatan Sumbersari Kabupaten Jember Students Perception Toward E-Commerce Through Facebook In Sumbersari Subdistrict District Of Jember. E-Journal Ekonomi Bisnis Dan Akuntansi, 4(1), 72-78.

Seprina, I., Suroyo, H., \& Komalasari, D. (n.d.). Pengaruh Efektivitas Penggunaan E-Commerce pada Peningkatan Motivasi Berwirausaha pada Siswa SMK Bina Jaya Palembang. Jurnal Sistem Informasi, Teknologi Informatika Dan Komputer, 8(2), 90-96.

Sofian, S. (2017). Penerapan Sistem Informasi E-Commerce Berbasis Web ( Studi Kasus Untuk Vendor Pernikahan ). JITEKH, 6(2), 52-57.

Yusuf, N. H., Rengkung, L. S., \& Ribka M Kumaat. (2018). Kajian Persepsi Konsumen terhadap Usaha Nasi Kuning Saroja di Kota Manado. AgroSosioekonomi Unsrat, 14(2), 57-66. https://doi.org/10.1017/CBO9781107415 324.004. 
Utami, et al. 2020

\section{LAMPIRAN}

Tabel 1. Persepsi UMKM Telur Asin tentang Sosialisasi Perancangan Website E-Siatik. Kategori Persepsi Skor Persepsi Jumlah Responden Persentase Skor Total

\begin{tabular}{lcccc}
\hline Sangat Setuju & 5 & 22 & (\%) & 110 \\
\hline Setuju & 4 & 9 & 22,5 & 36 \\
\hline Ragu-Ragu & 3 & 5 & 12,5 & 15 \\
\hline Tidak Setuju & 2 & 3 & 7,5 & 6 \\
\hline Sangat Tidak Setuju & 1 & 1 & 2,5 & 1 \\
\hline Total & & $\mathbf{4 0}$ & $\mathbf{1 0 0}$ & $\mathbf{1 6 8}$
\end{tabular}

Sumber: Data Penelitian Terolah, 2019

Tabel 2. Persepsi UMKM Telur Asin tentang Kemudahan Penggunaan Website E-Siatik. Kategori Persepsi Skor Persepsi Jumlah Responden Persentase Skor Total

\begin{tabular}{lcccc}
\hline Sangat Setuju & 5 & 2 & (\%) & 10 \\
\hline Setuju & 4 & 18 & 45 & 72 \\
\hline Ragu-Ragu & 3 & 11 & 27,5 & 33 \\
\hline Tidak Setuju & 2 & 8 & 20 & 16 \\
\hline Sangat Tidak Setuju & 1 & 1 & 2,5 & 1 \\
\hline Total & & $\mathbf{4 0}$ & $\mathbf{1 0 0}$ & $\mathbf{1 3 2}$
\end{tabular}

Sumber: Data Penelitian Terolah, 2019

Tabel 3. Persepsi UMKM Telur Asin tentang Kepraktisan Penggunaan Website E-Siatik. Kategori Persepsi Skor Persepsi Jumlah Responden Persentase Skor Total

\begin{tabular}{lcccc}
\hline Sangat Setuju & 5 & 3 & (\%) & \\
\hline Setuju & 4 & 14 & 3,5 & 56 \\
\hline Ragu-Ragu & 3 & 13 & 32,5 & 39 \\
\hline Tidak Setuju & 2 & 9 & 22,5 & 18 \\
\hline Sangat Tidak Setuju & 1 & 1 & 2,5 & 1 \\
\hline Total & & $\mathbf{4 0}$ & $\mathbf{1 0 0}$ & $\mathbf{1 2 9}$ \\
\hline
\end{tabular}

Sumber: Data Penelitian Terolah, 2019

Tabel 4. Persepsi UMKM Telur Asin tentang Kerumitan Penggunaan Website E-Siatik. Kategori Persepsi Skor Persepsi Jumlah Responden Persentase Skor Total

\begin{tabular}{lcccc}
\multicolumn{5}{c}{ (\%) } \\
\hline Sangat Tidak Setuju & 5 & 8 & 20 & 40 \\
\hline Tidak Setuju & 4 & 9 & 22,5 & 36 \\
\hline Ragu-Ragu & 3 & 20 & 50 & 60 \\
\hline Setuju & 2 & 1 & 2,5 & 2 \\
\hline Sangat Setuju & 1 & 2 & 5 & 2 \\
\hline Total & & $\mathbf{4 0}$ & $\mathbf{1 0 0}$ & $\mathbf{1 4 0}$
\end{tabular}

Sumber: Data Penelitian Terolah, 2019

Tabel 5. Persepsi UMKM Telur Asin tentang Keefektifan Penggunaan Website E-Siatik. Kategori Persepsi Skor Persepsi Jumlah Responden Persentase Skor Total

\begin{tabular}{lcccc} 
& \multicolumn{4}{c}{ (\%) } \\
\hline Sangat Setuju & 5 & 8 & 20 & 40 \\
\hline Setuju & 4 & 15 & 37,5 & 60 \\
\hline Ragu-Ragu & 3 & 12 & 30 & 36 \\
\hline Tidak Setuju & 2 & 3 & 7,5 & 6 \\
\hline Sangat Tidak Setuju & 1 & 2 & $\mathbf{1 0 0}$ & $\mathbf{1 4 4}$ \\
\hline Total & & $\mathbf{4 0}$ & & \\
\hline
\end{tabular}


Utami, et al. 2020

Sumber: Data Penelitian Terolah, 2019

Tabel 6. Persepsi UMKM Telur Asin tentang Tampilan Website E-Siatik. Kategori Persepsi Skor Persepsi Jumlah Responden Persentase

Skor Total

(\%)

\begin{tabular}{lcccc}
\hline Sangat Setuju & 5 & 9 & 22,5 & 45 \\
\hline Setuju & 4 & 12 & 30 & 48 \\
\hline Ragu-Ragu & 3 & 9 & 22,5 & 27 \\
\hline Tidak Setuju & 2 & 8 & 20 & 16 \\
\hline Sangat Tidak Setuju & 1 & 2 & 5 & 2 \\
\hline Total & & $\mathbf{4 0}$ & $\mathbf{1 0 0}$ & $\mathbf{1 3 8}$ \\
\hline
\end{tabular}

Sumber: Data Penelitian Terolah, 2019

Tabel 7. Persepsi UMKM Telur Asin tentang Warna Dasar Website E-Siatik. Kategori Persepsi Skor Persepsi Jumlah Responden Persentase Skor Total

\begin{tabular}{lcccc}
\hline Sangat Setuju & 5 & 10 & $(\%)$ & 25 \\
\hline Setuju & 4 & 18 & 45 & 72 \\
\hline Ragu-Ragu & 3 & 4 & 10 & 12 \\
\hline Tidak Setuju & 2 & 8 & 20 & 16 \\
\hline Sangat Tidak Setuju & 1 & 0 & 0 & 0 \\
\hline Total & & $\mathbf{4 0}$ & $\mathbf{1 0 0}$ & $\mathbf{1 5 0}$
\end{tabular}

Sumber: Data Penelitian Terolah, 2019

Tabel 8. Persepsi UMKM Telur Asin tentang Isi dan Fasilitas Website E-Siatik. Kategori Persepsi Skor Persepsi Jumlah Responden Persentase Skor Total

\begin{tabular}{lcccc} 
& & & $(\%)$ & \\
\hline Sangat Setuju & 5 & 25 & 62,5 & 125 \\
\hline Setuju & 4 & 5 & 12,5 & 20 \\
\hline Ragu-Ragu & 3 & 6 & 15 & 18 \\
\hline Tidak Setuju & 2 & 2 & 5 & 4 \\
\hline Sangat Tidak Setuju & 1 & 2 & 5 & 2 \\
\hline Total & & $\mathbf{4 0}$ & $\mathbf{1 0 0}$ & $\mathbf{1 6 9}$
\end{tabular}

Sumber: Data Penelitian Terolah, 2019

Tabel 9. Rekapitulasi Skor Total Persepsi tentang Pemanfaatan Website E-Siatik

\begin{tabular}{clc}
\hline No & \multicolumn{1}{c}{ Persepsi } & Total Skor \\
\hline 1 & Sosialisasi Website E-Siatik & 168 \\
\hline 2 & Kemudahan Penggunaan Website & 132 \\
\hline 3 & Kerumitan Penggunaan Website & 129 \\
\hline 4 & Kepraktisan Penggunaan Website & 140 \\
\hline 5 & Efektivitas Penggunaan Website & 144 \\
\hline 6 & Tampilan Website & 138 \\
\hline 7 & Warna Dasar Website & 150 \\
\hline 8 & Isi dan Konten Website & 169 \\
\hline & Skor Keseluruhan & $\mathbf{1 1 7 0}$ \\
\hline
\end{tabular}

Sumber: Data Penelitian Terolah, 2019 